\title{
Spatial Distribution and Factors Associated with Low birth weight in Ethiopia using data from Ethiopian Demographic and Health Survey 2016; Spatial and Multilevel analysis
}

Alemneh Mekuriaw Liyew ( $\nabla$ alemnehmekuriawliyew@gmail.com )

University of Gondar https://orcid.org/0000-0001-9034-6205

Malede Mequanent Sisay

University of Gondar

Achenef Asmamaw Muche

University of Gondar

\section{Research}

Keywords: low birth weight, spatial analysis, multi-level analysis, Ethiopia

Posted Date: September 4th, 2020

DOI: https://doi.org/10.21203/rs.3.rs-70101/v1

License: @ (i) This work is licensed under a Creative Commons Attribution 4.0 International License. Read Full License

Version of Record: A version of this preprint was published at BMJ Paediatrics Open on May 1st, 2021. See the published version at https://doi.org/10.1136/bmjpo-2020-000968. 


\section{Abstract \\ Background}

Low birth weight (LBW) is a leading cause of neonatal mortality. In Ethiopia, it is a public health problem that contributes to the majority of newborn deaths. To date, the effect of contextual factors on LBW was largely overlooked in Ethiopia. Besides, there is also limited evidence on the geographic variation of low birth weight in Ethiopia. Therefore, this study aimed to explore spatial distribution as well as individual and community-level factors associated with low birth weight in Ethiopia.

\section{Method:}

Secondary data analysis was conducted using the 2016 Ethiopian Demographic and Health Survey (EDHS) data. A total of 1502 neonates were included in this study. Spatial autocorrelation analysis was conducted to assess the spatial dependency of LBW. Besides, the spatial scan statistics and ordinary kriging interpolation were done to detect the local level clusters and to assess predicted risk areas respectively. Furthermore, a multi-level logistic regression model was fitted to determine individual and community-level factors associated with low birth weight. Finally, most likely clusters with log-likelihood ratio (LLR), relative risk and p-value from spatial scan statistics, and AOR with 95\% Cl for multi-level logistic regression model were reported.

\section{Results}

Low birth weight was spatially clustered in Ethiopia. Primary $(L L R=11.57 ; P=0.002)$ clusters were detected in the Amhara region. It showed that neonates within the spatial window had 2.66 times higher risk of being LBW baby as compared to those outside the window. Besides, secondary $($ LLR $=11.4$; $P=$ $0.003 ; \mathrm{LLR}=10.14, \mathrm{P}=0.0075)$ clusters were identified at Southwest Oromia, north Oromia, south Afar, and Southeast Amhara regions. Neonates who were born from severely anemic $(\mathrm{AOR}=1.47 ; 95 \% \mathrm{Cl} 1.04,2.01)$, and uneducated $(\mathrm{AOR}=1.82 ; 95 \% \mathrm{Cl} 1.12,2.96)$ mothers, as well as those who were born before 37 weeks of gestation $(\mathrm{AOR}=5.91 ; 95 \% \mathrm{Cl} 3.21,10.10)$ and females $(\mathrm{AOR}=1.38 ; 95 \% \mathrm{Cl} 1.04,1.84)$, had significantly higher odds of being low birth weight babies.

\section{Conclusion}

The high-risk areas of low birth weight were detected in Afar, Amhara, and Oromia regions. Therefore, targeting the policy interventions in those risk areas by focusing on the improvement of maternal education, strengthening anemia control programs and elimination of modifiable causes of prematurity could be vital for reduce the low birth weight disparity in Ethiopia.

\section{Background}

World health organization (WHO) defined low birth weight (LBW) as weight at birth less than 2,500 grams (1). It is strongly linked to neonatal mortality. Globally neonatal deaths accounted for $46 \%$ of all under-five deaths of which $38 \%$ occurred in sub-Saharan Africa. Ethiopia is the one among five countries those account for about half of all global neonatal deaths (2). The 2016 EDHS report shows that the neonatal mortality rate to be $29 / 1000$ live births. Thus, Ethiopia fails to achieve the millennium development goal target for neonatal mortality $(2,3)$.

Besides, Low birth weight directly or indirectly accounts for about $60-80 \%$ of neonatal mortality in Asia (4). Another study shows that LBW babies to be highly Vulnerable to death than heavier ones (5). In Ethiopia, Low birth weight accounts about $4 \%$ of total deaths (6).

The consequence of LBW is not limited to neonatal and infant mortality but it also results in physical and developmental health problems in subsequent childhood and adulthood life. Thus, it leads to poor childhood growth and a higher incidence of adulthood chronic diseases like type 2 diabetes, hypertension, and cardiovascular disease (7). This indicates that LBW is a basement for the majority of adulthood chronic diseases. It has also long term consequences like poor cognitive function, academic underachievement and impaired behavior $(8,9)$. Moreover, LBW is a summary measure of multifaceted public health problems such as maternal malnutrition, ill-health and poor pregnancy-related health service utilization $(7,10)$

Globally, more than 20 million infants are born being low birth weight (LBW). Among these

nearly half (48\%) of LBW, births occur in southern Asia. In sub-Saharan Africa, the number of LBW live births is estimated to have increased from 4.4 million in 2000 to 5.0 million in 2015 (11). Furthermore, it is notified as a continuing public health challenge in this region (12). These rates are high, even though the data on low birth weight remain limited as many deliveries occur at home or small health clinics and were not reported in official figures, which may result in an underestimation of the prevalence. Therefore, WHO incorporated as a third target to achieve a $30 \%$ reduction in low birth weight incidence by 2025 (13).

Even though data on low birth weight was limited due to low institutional delivery in Ethiopia, the prevalence of low birth weight was increased by $5 \%$ from 2000 (14) to 2016 (15). Furthermore, the evidence from a systematic review and meta-analysis shows that the pooled prevalence of low birth weight to be $17.3 \%$ (16). In addition, the prevalence of LBW is different across different geopolitical regions in Ethiopia (17-19). This indicates that the variation in the prevalence of LBW across different administrative regions could be an insight to identify risk (hotspot) areas by using spatial technology.

A research conducted in different countries on determinants of LBW showed that various socio-demographic, socioeconomic, maternal health service-related, and community-related factors to be predictors of low birth weight $(17,20,21)$. In Ethiopia, prior studies have been done to identify sociodemographic, pregnancy, and maternal health service-related factors (20-23). Even though low birth weight was affected by factors operating at both individual and 
community levels, none of the studies have tried to look at the factors that affect LBW at community and individual levels simultaneously. Furthermore, there was limited evidence on the spatial distribution of low birth weight in Ethiopia.

Therefore, this study was aimed at identifying both individual and community-level factors associated with low birth weight simultaneously by applying a multi-level modeling approach. Besides, it tried to identify high risk (hot spot areas) of low birth weight by applying spatial analysis. Thus, the implication of this study is to provide evidence for policymakers (nationwide data) to narrow the geographic disparity of low birth weight across regions in Ethiopia by strengthening maternal and child health intervention programs.

\section{Methods}

\section{Data source}

Secondary data analysis was employed to identify spatial distribution and factors associated with low birth weight. An authorization letter for the use of this data was obtained from Measure DHS and the dataset was downloaded from measure DHS website www.measuredhs.com. The survey covered all the nine regions and two administrative cities in Ethiopia (Fig.1).

The participants were selected using a stratified two-stage cluster sampling technique. The survey collected information from a nationally representative sample of 16583 eligible women within 645 enumeration areas. The full method applied to the data collection procedure for EDHS 2016 was published elsewhere (15). For this study, to adjust for over or under-sampling which might occur due to the sampling nature of Demographic and health survey we applied sampling weight. This was considered to produce a nationally representative sample since those regions with a larger population could be undersampled whereas those regions with a small population could be oversampled whenever sampling weight was not applied. Therefore, the final weighted sample size for our analysis was 1502 neonates born five years preceding the survey nested within 542 communities (clusters) for multilevel analysis. Since clusters with no recorded geographic coordinate were excluded, the spatial analysis was based on 441 clusters. The weighted proportion of LBW per cluster was computed for further spatial analysis.

\section{Study Variables}

\section{Dependent variable}

The main outcome variable of this study was birth weight. Data on the birth weight of children were collected from mothers who gave birth within 5 years before the survey either by accessing birth weight through record review or by the mother's report by recalling the measured weight of the child at birth. The births without recorded birth weight were excluded from the study. Finally, it was categorized as birth weight $\geq 2.5 \mathrm{~kg}$ or $<2.5 \mathrm{~kg}$ for further analysis.

\section{Independent variables}

The determinants of low birth weight were extracted after reviewing literature at a global level. Maternal Age, maternal Educational status, sex of neonate, wealth index, media exposure, number of ANC visit, gestational age, Maternal anemia, Maternal BMI, Iron supplementation, maternal height, birth order, birth interval, and cesarean delivery were individual-level predictors.

Whereas, community poverty, community media exposure, community women education, region, and place of residence were community-level variables. The aggregate community level explanatory variables were constructed by aggregating individual-level characteristics at the community (cluster) level. They were dichotomized as high or low based on the distribution of the proportion values computed for each community after checking the distribution by using the histogram. If the aggregate variable was normally distributed mean value and if not, normally distributed median value was used as a cut-off point for the categorization.

Therefore, the community poverty level was categorized as high if the proportion of women from the two lowest wealth quintiles in a given community was $70-100 \%$ and low if the proportion was less than $70 \%$. Community media exposure was categorized as low if the proportion of women exposed to media in the community was $0-83.33 \%$ and categorized as high if the proportion was $83.33-100 \%$, Community Women education was categorized as low if the proportion of women with no formal education in the community was $14.83 \%-100 \%$ and categorized as high if the proportion was $0-14.83 \%$.

\section{Spatial analysis}

\section{Spatial autocorrelation analysis}

The Global Moran's I statistic test was used to measure whether the low birth weight patterns were randomly distributed, dispersed, or clustered in Ethiopia. The calculated Moran's I values close to -1 indicate disease dispersed, whereas I close to +1 indicate disease clustered and if the I value zero the disease is distributed randomly A statistically significant Moran's I $(p<0.05)$ leads to rejection of the null hypothesis(random distribution of the diseases in the study area) and implies the presence of spatial autocorrelation $(22,23)$.

\section{Spatial scan statistical analysis}

Spatial Scan statistical method is commonly recommended that it is better than others in detecting local clusters and has higher power as compared to available spatial statistical methods (24). Thus, the presence of statistically significant spatial hotspots/clusters of low birth weight was tested by using 
spatial scan statistical analysis. This method uses a scanning window that moves across the study area $(25,26)$. Low birth weight newborns were taken as cases and those were not born being LBW were taken as controls to fit the Bernoulli model. The number of cases in each location had Bernoulli distribution and the model requires data with or without a disease.

The default maximum spatial cluster size of $<50 \%$ of the population was used, as an upper limit, which allowed both small and large clusters to be detected and ignored clusters that contained more than the maximum limit. For each potential cluster, a likelihood ratio test statistic was used to determine if the number of observed LBW cases within the potential cluster was significantly higher than expected or not. The primary and secondary clusters were identified and assigned p-values and ranked based on their likelihood ratio test, based on 999 Monte Carlo replications $(27,28)$.

\section{Spatial interpolation}

It is very expensive and laborious to collect reliable data in all areas of the country to know the burden of certain events. Therefore, part of a certain area can be predicted by using observed data using a method called interpolation. The spatial interpolation technique was used to predict low birth weight on the unsampled areas in the country based on sampled enumeration areas. Therefore, ordinary Kriging interpolation method was employed to estimate the burden of low birth weight in unsampled areas since it incorporates the spatial autocorrelation and it statistically optimizes the weight.

\section{Multi-level logistic regression analysis}

Because of the hierarchical nature of data and the dichotomous outcome variable, the multi-level logistic regression model was fitted after testing the significance of the community variance. The individual and community level variables associated with LBW were checked independently in the bivariable multilevel logistic regression model and Variables which were statistically significant at p-value 0.2 in the bivariable multilevel logistic regression analysis were considered for the individual and community level model adjustments. Besides, Sampling weight was applied as part of complex survey design to produce reliable estimates.

\section{Model building}

Four models were fitted. The first was the null model containing no exposure variables which was used to check variation in community and provide evidence to assess random effects at the community level. The second model was the multivariable model adjustment for individual-level variables and model three was adjusted for community-level factors. In the fourth model, both individual and community-level variables were fitted with the outcome variable.

\section{Parameter estimation method}

The fixed effects (a measure of association) were used to estimate the association between the likelihood of low birth weight and explanatory variables at both community and individual level s and were reported as odds ratio with $95 \%$ confidence interval. Regarding the measures of variation (random-effects) intracluster correlation coefficient (ICC), Proportional Change in Community Variance (PCV), and median odds ratio (MOR) were used.

\section{Results}

In this study, a total of 1502 neonates were included. Of these, nearly half (51\%) were males and $28.84 \%$ were born from mothers with no formal education. The Mean age of their mothers was 29 [SD $= \pm 6.08$ ] years. About two-thirds $(67 \%)$ of neonates were born from mothers who were exposed to media. About $14.31 \%$ and $43.21 \%$ of neonates were born from severely anemic and mothers who didn't receive iron during pregnancy respectively. Regarding the antenatal care (ANC) visit more than half (56\%) of neonates were born from mothers who have more than three ANC visits. The majority (97\%) of neonates were born after 37 weeks of gestation. Looking at the wealth index, nearly two-thirds $(68 \%)$ of neonates were from rich households (Table1).

\section{Community-level characteristics of participants}

A total of 452 communities (clusters) were included in this study. About two-thirds (67.44\%) of neonates were from a community with a low poverty level and nearly half $(51.33 \%)$ of them were from rural communities. Regarding community women education $42 \%$ of neonates were from communities with high women literacy (Table2).

Table 2: Community-level characteristics of study subjects, EDHS $2016(\mathrm{n}=1502)$. 


\begin{tabular}{|llll|}
\hline Low Birth weight & & & \\
\hline Variables & Yes & No & Total (\%) \\
\hline Community poverty level & & & \\
\hline Low & $128(12.64)$ & $885(87.36)$ & $1013(67.44)$ \\
\hline High & $70(14.32)$ & $419(85.68)$ & $489(32.56)$ \\
\hline Community media exposure & & & \\
\hline Low & $112(15.09)$ & $630(84.91)$ & $742(49.41)$ \\
\hline High & $86(11.32)$ & $674(88.68)$ & $760(50.59)$ \\
\hline Community women education & & & \\
\hline Low & $79(10.92)$ & $644(89.08)$ & $723(48.14)$ \\
\hline High & $119(15.27)$ & $660(84.73)$ & $779(51.86)$ \\
\hline Place of residence & & & \\
\hline Urban & $80(10.94)$ & $651(89.06)$ & $731(48.67)$ \\
\hline Rural & $118(15.31)$ & $653(84.69)$ & $771(51.33)$ \\
\hline
\end{tabular}

\section{Spatial distribution of low birth weight in Ethiopia}

As indicated in figure 2, the spatial variation of the proportion of low birth weight was mapped. Thus, the high prevalence of low birth weight was observed in Afar, North-west Amhara, Northeast SNNP, central part of Oromia region and Somali regional states of Ethiopia. (Fig 2).

Fig 2: Spatial distribution of low birth weight in Ethiopia.

\section{Spatial autocorrelation of low birth weight in Ethiopia}

This study identified that the spatial distribution of low birth weight was found to be clustered in Ethiopia with Global Moran's I =0.56 and $p=0.001$ (Fig 3 ). The clustered patterns (on the right sides) show high rates of low birth weight occurred over the study area. The Z-score of 45.57 indicated that there is less than $1 \%$ likelihood that this clustered pattern could be the result of random chance.

Fig 3: Spatial autocorrelation of low birth weight in Ethiopia, EDHS 2016.

\section{Spatial scan statistics of low birth weight in Ethiopia}

Spatial scan statistics identified 40 significant clusters of which 15 were primary clusters and 25 were secondary clusters. The primary clusters' spatial window was located in the North West Amhara and Northeast part of BenishangulGumuz, which was centered at 11.57418N, 36.498123 E with 122.56km radius, and Log-Likelihood ratio (LLR) of 11.82 , at $\mathrm{p}<0.01$. It showed that neonates within the spatial window had 2.66 times higher risk of being LBW baby as compared to those outside the window.

Two other significant spatial windows were located in southwest Oromia and at the border of southeast Amhara, south Afar, and northern part of Oromia regions. The one located in southwest Oromia region was centered at 7.192884N,39.02565E with 30.83 radius, LLR of 11.43 and p-value 0. 003. Neonates within this scanning window had 4.82 times higher risk of being LBW than those outside the scanning window. The third scanning window which was located at the border of three regions (Amhara,Afar and Oromia) was centered at 10.143320N,39.718498E with 158.43km radius and log-likelihood ratio (LLR) of 10.37 at $p$-value 0 . 0075. Thus, the likelihood of being low birth weight among neonates inside this scanning window was 2.52 times higher as compared to those outside the window. (Fig 4, Table 3).

Fig. 4: The spatial scanning statistics of LBW in Ethiopia, 2016.

Table 3. significant spatial clusters of low birth weight in Ethiopia EDHS 2016.

\begin{tabular}{|c|c|c|c|c|c|c|c|}
\hline clusters & Enumeration areas detected & population & cases & LLR & RR & Coordinate/radius & $\mathrm{p}$ \\
\hline $1^{*}$ & $259,602,541,386,548,361,515,498,516,109,292,533,73,167,52$ & 94 & 30 & 11.82 & 2.66 & $11.574184 \mathrm{~N}, 36.498123 \mathrm{E} / 122.56 \mathrm{~km}$ & 0 \\
\hline 2 ** & 26,589 & 18 & 11 & 11.41 & 4.82 & $\begin{array}{l}7.192884 \text { N, } 39.025650 \text { E) / } 30.83 \\
\text { km }\end{array}$ & 0 \\
\hline $3 * \star$ & $\begin{array}{l}637,310,295,484,624,135,617,230,18,423,121,616,49, \\
345,254,611,71,40,303,90,287,402,560\end{array}$ & 95 & 29 & 10.37 & 2.52 & $\begin{array}{l}10.143320 \mathrm{~N}, 39.718498 \mathrm{E}) / \\
158.43 \mathrm{~km}\end{array}$ & 0 \\
\hline
\end{tabular}

*=primary clusters;**=secondary clusters 


\section{Spatial interpolation of LBW in Ethiopia in 2016}

In ordinary kriging spatial interpolation zone1, zone4 and zone 5 in Afar region; Waghimra, Semen Gonder, and Awi in Amhara region; mirab welega and mirab Arsi in Oromia region; Gurage, silti and debub omo in SNNP region were areas at high-risk of low birth weight (Fig. 5).

Fig 5: the ordinary kriging spatial interpolation of LBW across regions in Ethiopia, EDHS 2016.

\section{Multilevel logistic regression analysis}

\section{Random effect analysis results}

In the null model, variance component analysis was performed to decompose the total variance of LBW. The cluster-level variance which indicates the total variance of LBW that can be attributed to the context of the community in which the mothers were living was estimated. The applicability of multi-level mixedeffects logistic regression model in the analysis was justified by the significance of the community-level variance [community variance $=0.435$; standard error $(S E)=0.19 ; P$-value $=0.001]$, indicating the existence of significant differences between communities regarding LBW incidence. The community variance was expressed as the intracluster correlation coefficient (ICC) and the median odds ratio (MOR). The ICC was 0.117 which revealed that $11.7 \%$ of the total variance of LBW in Ethiopia can be attributed to the context of the communities where the mothers were dwelling. Since it was greater than 0.05 the nuisance of clustering was considered to produce reliable estimates (29). Moreover, the MOR was $1.88(95 \% \mathrm{Cl} 1.27,2.34)$ which implied that the odds of having LBW was increased by $88 \%$ when mothers moved from low to high-risk communities.

In the full model community variance (community variance= 0.308; SE 0.17; P-value, 0.01), MOR $1.60(95 \% \mathrm{Cl} 1.16,2.14)$ and ICC $(0.08)$ remained significant but reduced. About $8 \%$ of the total variance of LBW that can be attributed to the contextual-level factors remained significant even after considering some contextual risk factors for LBW. The PCV in this model was $29.2 \%$. This showed that $29.2 \%$ of community variance observed in the null model was explained by both community and individual-level variables. Regarding model comparison, we used the loglikelihood ratio and deviance. The model with the highest loglikelihood or lowest deviance value (Model IV) was the best-fitted model. Consequently, factors that were significant in this model were further considered (Table 4).

Table 4: Random effects and model fitness

\begin{tabular}{|lllll|}
\hline Random effects & Model I & Model II & Model III & Model IV \\
\hline Community variance (SE) & $0.435^{\star}(0.187)$ & $0.323^{*}(0.177)$ & $0.40 *(0.18)$ & $0.308^{\star}(0.17)$ \\
\hline ICC $(\%)$ & 11.70 & 9.0 & 10.0 & 8.0 \\
\hline PCV $(\%)$ & Reff & 25.3 & 8.0 & 29.2 \\
\hline MOR (95\%CI) & $1.88(1.27,2.34)$ & $1.72(1.10,2.16)$ & $1.83(1.23,2.28)$ & $1.70(1.16,2.14)$ \\
\hline Model fitness & Model I & Model II & Model III & Model IV \\
\hline Log likelihood & -732.80 & -701.00 & -729.20 & -688.09 \\
\hline Deviance(-2LLR) & 1465.60 & 1402.00 & 1458.40 & 1376.18 \\
\hline
\end{tabular}

\section{Fixed effects analysis results}

In the bi-variable mixed-effects logistic regression analysis wealth index, maternal age, number of ANC visit, gestational age, media exposure, mother's education, maternal BMI, maternal anemia, sex of infant, iron supplementation during pregnancy, region place of residence, community poverty level, community illiteracy level, community media exposure, and community women education were significant at $p$-value $<0.2$ and fitted for Multi-variable analysis.

Multivariable multilevel logistic regression analysis was fitted to identify factors associated with low birth weight. In the final model (best-fitted model to data) maternal education, maternal anemia, gestational age, and sex of the neonate were significantly associated with low birth weight. Therefore, the odds of being low birth weight baby for neonates who were born from women with no education was $1.82(\mathrm{AOR}=1.82 ; 95 \% \mathrm{Cl} 1.12,2.96)$ times higher as compared to those born from women who had secondary and above education. The neonates who were born from women who were severely anemic had 1.47 (AOR=1.47; $95 \%$ $\mathrm{Cl} 1.04,2.01)$ times higher odds of being low birth weight baby as compared to those from non-anemic mothers.

Regarding the duration of pregnancy, the likelihood of being low birth weight baby among preterm neonates was $5.91(\mathrm{AOR}=5.91 ; 95 \% \mathrm{Cl} 3.21,10.10)$ times higher as compared to term or post-term neonates. Moreover, the female neonate had $38 \%(A O R=1.38 ; 95 \% \mathrm{Cl} 1.04,1.84)$ increased odds of being low birth weight baby as compared to male neonates (Fig 5).

\section{Discussion}

In this study, low birth weight was nonrandom and it was affected by sociodemographic and pregnancy-related characteristics of mothers. The spatial autocorrelation analysis revealed that low birth weight had spatial dependency (Moran'l $=0.56$, p-value: 0.01 ) in Ethiopia. This might be due to the variation in maternal health service utilization during pregnancy and variation in health service coverage across different regions in Etiopia.

The spatial scan statistics identified fifteen most likely clusters at the eastern part of Amhara and northern border of Benshangul gumuz region and 25 secondary clusters in the south Afar, southwest Amhara and northern part of Oromia region. The possible explanation could be the large disparity in health 
service access and affordability especially in those remote areas. This is supported by the fact that health service access is the major challenge in rural health in the countries where the majority of the population lives in rural areas like Ethiopia (30). Thus, since SaTtscan is a powerful analytic tool (27) that identifies most likely clusters for intervention, especially in resource-limited areas, these spatial patterns and clustering of events, provide important information for the development and refinement of geographically based and population-specific prevention programs for maternal and child health to reduce LBW risk.

This study also highlighted the predicted risk of low birth weight in Ethiopia based on the sampled data. Accordingly, zone1, zone4 and zone 5 in Afar region; Wag himra, Semen Gonder and Awi in Amhara region;mirab welega and mirab Arsi in Oromia region;Gurage,silti and debub omo in SNNP region were areas at high-risk of low birth weight. This might be due to variation in maternal health service utilization and environmental factors (drought) like in Wag Himra which might have affected maternal nutrition during pregnancy.

This study found that neonates who were born from severely anemic mothers had higher odds of being LBW baby as compared to those who were born from nonanemic mothers. This finding is consistent with studies conducted in India $(31,32)$ and Ethiopia $(33,34)$. This might be due to the fact that anemia during pregnancy, especially if severe, could affect oxygen supply to the fetus and thus interferes with normal intrauterine growth or pregnancy duration which possibly leads to low birth weight (35).

Similarly, the likelihood of being LBW baby was higher among neonates who were born from women with no formal education as compared to those who were born from educated women. This finding was in agreement with studies conducted in Malawi (36), Bangladesh (21), India (20), and northwest Ethiopia (17). This may be due to the fact that uneducated mothers are relatively at low living standards and they might have poor maternal nutrition during pregnancy. In developing countries, it was found that poor gestational nutrition was found to be a major determinant of intrauterine growth restriction which might result in LBW delivery (35).

Regarding the duration of pregnancy, this study revealed that odds of being low birth weight baby among neonates who were born before 37 weeks of gestation was nearly six-folds higher as compared to those who were after 37 weeks of gestation. This result was concordant with studies conducted in Pakistan (37), Kenya (38), northwest (39), and southwest (18) Ethiopia. The possible explanation might be babies who were delivered in earlier periods of gestation were less likely to have full fetal development. Furthermore, evidence from the systematic review showed that gestational duration was found to be the most proximal cause of low birth weight (35).

Of the particular interest of this study is the association of sex of the neonate with low birth weight. Thus, female neonates had higher odds of being low birth weight babies as compared to male neonates. This result is in line with the findings in Ghana (40) and Nepal (41). The association could be explained by the pathophysiologic mechanism in the uterus. The evidence shows that females had a higher risk of developing intrauterine growth restriction (IUGR) than males which probably results in low birth weight (35).

This study was based on the most recent EDHS data with a nationally representative large sample size based on a multilevel modeling approach. The sampling weight was applied to produce appropriate standard errors and then a reliable estimate. Despite the above strengths, the study had the following limitations. Some participants, data on birth weight was collected by mothers' reports by recalling weight of their child at birth (recall bias) which may over or underestimate the results. Second, since it is secondary data analysis, those behavioral factors which will affect the outcome of pregnancy were not included.

\section{Conclusion}

Low birth weight was spatially clustered in Ethiopia. High-risk areas were identified Afar, Amhara, Oromia, BenshangulGumuz, the northern part of South nation nationality and people's regions. Regarding factors, maternal anemic, maternal education, prematurity and sex of neonate were significantly associated with low birth weight. Therefore, targeting the policy interventions in those geogrsphically low birth weight risk areas by focusing on the improvement of maternal education, strengthening anemia control programs and elimination of modifiable causes of prematurity could be vital to reducing the low birth weight disparity in Ethiopia.

\section{Abbreviations}

ANC: Antenatal care; AOR:adjusted odds ratio; EDHS:Ethiopian demographic and health survey; LBW:Low birth weight; MOR:median odds ratio; IUGR:Intrauterine growth restriction.

\section{Declarations}

\section{Ethical consideration}

Ethical clearance was approved by an Institutional ethical Review committee of the Institute of Public Health, College of Medicine and Health Sciences and the University of Gondar. Permission for data access was obtained from measure demographic and health survey through online request at http://www.dhsprogram.com. The authorization letter was also gained from measure DHS. Finally, No information obtained was disclosed to third body.

\section{Consent for publication}

Not applicable

\section{Availability of data and materials}


All the data underlying the findings were fully available in the manuscript. We declare that the authors did not have any special access privileges that others would not have. The data are publicly available upon reasonable request of the DHS MEASURE website through archive@measuredhs.com. after being authorized user.

\section{Competing Interests}

The authors declare that they have no competing interests.

\section{Funding}

No funding support was provided

\section{Authors' contributions}

AML: Wrote the research proposal, conducted the data analysis, interpreted the results and organized the manuscript. AAM and MMS: Involved in designing the study, revising the proposal, guiding the statistical analysis, and write up of the manuscript. All authors read and approved the final manuscript.

\section{Acknowledgments}

The authors would like to thank measure DHS for their permission to access the DHS datasets

\section{References}

1. World Health Organization. International statistical classification of diseases and related health problems: World Health Organization; 2004.

2. Hug L, Sharrow D, You D. Levels \& trends in child mortality: report 2017. Estimates developed by the UN Inter-agency Group for Child Mortality Estimation. 2017.

3. Central Statistical Agency (CSA) [Ethiopia] and ICF. Ethiopia Demographic and Health Survey 2016. Addis Ababa, Ethiopia, and Rockville, Maryland, USA: CSA and ICF.2016.

4. Lawn JE, Cousens S, Zupan J, Team LNSS. 4 million neonatal deaths: when? Where? Why? The lancet. 2005;365(9462):891-900.

5. Kramer MS, Barros FC, Demissie K, Liu S, Kiely J, Joseph K. Does reducing infant mortality depend on preventing low birthweight? An analysis of temporal trends in the Americas. Paediatric and perinatal epidemiology. 2005;19(6):445-51.

6. world health organization. low birth weight deaths in Ethiopia 2017 [21/2/2019]. Available from: https://www.worldlifeexpectancy.com/ethiopia-lifeexpectancy.

7. Wardlaw TM. Low birthweight: country, regional and global estimates: Unicef; 2004.

8. Jaekel J, Eryigit-Madzwamuse S, Wolke D. Preterm toddlers' inhibitory control abilities predict attention regulation and academic achievement at age 8 years. The Journal of pediatrics. 2016;169:87-92. e1.

9. Hack M, Breslau N, Weissman B, Aram D, Klein N, Borawski E. Effect of very low birth weight and subnormal head size on cognitive abilities at school age. New England Journal of Medicine. 1991;325(4):231-7.

10. Hack M, Flannery DJ, Schluchter M, Cartar L, Borawski E, Klein N. Outcomes in young adulthood for very-low-birth-weight infants. New England Journal of Medicine. 2002;346(3):149-57.

11. Blencowe H, Krasevec J, de Onis M, Black RE, An X, Stevens GA, et al. National, regional, and worldwide estimates of low birthweight in 2015 , with trends from 2000: a systematic analysis. The Lancet Global Health. 2019.

12. World Health Organization. Guidelines on optimal feeding of low birth-weight infants in low-and middle-income countries: World Health Organization; 2011.

13. World Health Organization. WHA global nutrition targets 2025: low birth weight policy brief. 2014. 2014.

14. 2006. CSAEaOM. Ethiopia Demographic and Health Survey 2005. . Addis Ababa, Ethiopia and Calverton, Maryland, USA: Central Statistical Agency and ORC Macro. , 2005.

15. Central Statistical Agency (CSA) [Ethiopia] and ICF. Ethiopia Demographic and Health Survey 2016: HIV Report. . Addis Ababa, Ethiopia, and Rockville, Maryland, USA: CSA and ICF., 2016.

16. Endalamaw A, Engeda EH, Ekubagewargies DT, Belay GM, Tefera MA. Low birth weight and its associated factors in Ethiopia: a systematic review and meta-analysis. Italian journal of pediatrics. 2018;44(1):141.

17. Tafere TE, Afework MF, Yalew AW. Providers adherence to essential contents of antenatal care services increases birth weight in Bahir Dar City Administration, north West Ethiopia: a prospective follow up study. Reproductive health. 2018;15(1):163.

18. Tema T. Prevalence and determinants of low birth weight in Jimma Zone, Southwest Ethiopia. East African medical journal. 2006;83(7):366.

19. Gebregzabiherher Y, Haftu A, Weldemariam S, Gebrehiwet $H$. The prevalence and risk factors for low birth weight among term newborns in Adwa General Hospital, Northern Ethiopia. Obstetrics and gynecology international. 2017;2017.

20. Mandal A. Prevalence of low birth Key words: Low-birth weight, Prevalence, Factors, Howrah. Corresponding author. 2018.

21. Khan JR, Islam MM, Awan N, Muurlink O. Analysis of low birth weight and its co-variants in Bangladesh based on a sub-sample from nationally representative survey. BMC Pediatr. 2018;18. 
22. Pfeiffer D, Robinson TP, Stevenson M, Stevens KB, Rogers DJ, Clements AC. Spatial analysis in epidemiology: Oxford University Press Oxford; 2008.

23. Zulu LC, Kalipeni E, Johannes E. Analyzing spatial clustering and the spatiotemporal nature and trends of HIV/AIDS prevalence using GIS: the case of Malawi, 1994-2010. BMC infectious diseases. 2014;14(1):285.

24. Song C, Kulldorff M. Power evaluation of disease clustering tests. International journal of health geographics. 2003;2(1):9.

25. Tiwari N, Adhikari C, Tewari A, Kandpal V. Investigation of geo-spatial hotspots for the occurrence of tuberculosis in Almora district, India, using GIS and spatial scan statistic. International journal of health geographics. 2006;5(1):33.

26. Naish S, Tong S, editors. Hot spot detection and spatio-temporal dynamics of dengue in Queensland, Australia. ISPRS Technical Commission VIII Symposium; 2014: International Society of Photogrammetry and Remote Sensing (ISPRS).

27. Kulldorff M. SaTScanTM user guide. Boston; 2006.

28. Alemu K, Worku A, Berhane Y, Kumie A. Spatiotemporal clusters of malaria cases at village level, northwest Ethiopia. Malaria journal. $2014 ; 13(1): 223$.

29. Huang FL. Alternatives to multilevel modeling for the analysis of clustered data. The Journal of Experimental Education. 2016;84(1):175-96.

30. Strasser R. Rural health around the world: challenges and solutions. Family practice. 2003;20(4):457-63.

31. Kumar SG, Kumar HH, Jayaram S, Kotian M. Determinants of low birth weight: a case control study in a district hospital in Karnataka. The Indian Journal of Pediatrics. 2010;77(1):87-9.

32. Patel A, Prakash AA, Das PK, Gupta S, Pusdekar YV, Hibberd PL. Maternal anemia and underweight as determinants of pregnancy outcomes: cohort study in eastern rural Maharashtra, India. BMJ open. 2018;8(8):e021623.

33. Ahmed S, Hassen K, Wakayo T. A health facility based case-control study on determinants of low birth weight in Dassie town, Northeast Ethiopia: the role of nutritional factors. Nutrition journal. 2018;17(1):103.

34. Alemu T, Umeta M. Prevalence and Predictors of "Small Size" Babies in Ethiopia: In-depth Analysis of the Ethiopian Demographic and Health Survey, 2011. Ethiop J Health Sci. 2016;26(3):243-50.

35. Kramer MS. Determinants of low birth weight: methodological assessment and meta-analysis. Bulletin of the world health organization. 1987;65(5):663.

36. Muula A, Siziya S, Rudatsikira E. Parity and maternal education are associated with low birth weight in Malawi. African health sciences. 2011;11(1).

37. Badshah S, Mason L, McKelvie K, Payne R, Lisboa PJ. Risk factors for low birthweight in the public-hospitals at Peshawar, NWFP-Pakistan. BMC public health. 2008;8(1):197.

38. Nyamasege C, Kimani-Murage E, Wanjohi M, Kaindi D, Ma E, Fukushige M, et al. Determinants of low birth weight in the context of maternal nutrition education in urban informal settlements, Kenya. Journal of developmental origins of health and disease. 2018:1-9.

39. Asmare G, Berhan N, Berhanu M, Alebel A. Determinants of low birth weight among neonates born in Amhara Regional State Referral Hospitals of Ethiopia: unmatched case control study. BMC research notes. 2018;11(1):447.

40. Manyeh AK, Kukula V, Odonkor G, Ekey RA, Adjei A, Narh-Bana S, et al. Socioeconomic and demographic determinants of birth weight in southern rural Ghana: evidence from Dodowa Health and Demographic Surveillance System. BMC pregnancy and childbirth. 2016;16(1):160.

41. Acharya D, Singh JK, Kadel R, Yoo SJ, Park JH, Lee K. Maternal Factors and Utilization of the Antenatal Care Services during Pregnancy Associated with Low Birth Weight in Rural Nepal: Analyses of the Antenatal Care and Birth Weight Records of the MATRI-SUMAN Trial. Int J Environ Res Public Health. 2018;15(11).

\section{Tables}

Table 1: Individual-level characteristics of participants, EDHS 2016 (n=1502). 


\begin{tabular}{|c|c|c|c|}
\hline \multicolumn{4}{|c|}{ Low birth weight } \\
\hline Independent variables & Yes (\%) & No $(\%)$ & Total (\%) \\
\hline \multicolumn{4}{|l|}{ Maternal age } \\
\hline $15-19$ & $17(28.81)$ & 42(71.19) & $59(3.92)$ \\
\hline $20-24$ & $30(9.3)$ & 293(90.7) & $323(21.50)$ \\
\hline $25-29$ & $77(14.36)$ & 459(85.64) & $536(35.68)$ \\
\hline $30-34$ & $44(13.62)$ & 279(86.38) & $323(21.50)$ \\
\hline $35-39$ & $21(11.30)$ & 165(88.70) & 186(12.38) \\
\hline $40-49$ & $9(12.00)$ & $66(88.00)$ & $75(4.99)$ \\
\hline \multicolumn{4}{|c|}{ Women educational level } \\
\hline No education & $79(18.21)$ & 355(81.79) & $434(28.89$ \\
\hline Primary & $63(11.03)$ & $508(88.97)$ & $571(38.01)$ \\
\hline Secondary andabove & $56(11.27)$ & $441(88.73)$ & 497(33.08) \\
\hline \multicolumn{4}{|l|}{ Gestational age } \\
\hline$<37$ weeks & $21(45.65)$ & $25(54.35)$ & $46(3.07)$ \\
\hline$\geq 37$ weeks & $177(12.16)$ & $1279(87.84)$ & 1456(96.93) \\
\hline \multicolumn{4}{|l|}{ Iron supplementation } \\
\hline Yes & $108(12.66)$ & 745(87.34) & $853(56.79)$ \\
\hline No & $90(13.86)$ & $559(86.14)$ & $649(43.21)$ \\
\hline \multicolumn{4}{|l|}{ number of ANC visit } \\
\hline$<4$ visits & 104(15.95) & $548(84.05)$ & $652(43.41)$ \\
\hline$\geq 4$ visits & $94(11.05)$ & 756(88.95) & $850(56.59)$ \\
\hline \multicolumn{4}{|l|}{ Media exposure } \\
\hline Yes & $126(12.52)$ & $880(87.48)$ & 1006(66.98) \\
\hline No & $72(14.51)$ & 424(85.49) & 496(33.02) \\
\hline \multicolumn{4}{|l|}{ Maternal BMI } \\
\hline Underweight & $39(19.02)$ & 166(80.98) & 205(13.65) \\
\hline Normal & 133(13.09) & 883(86.91) & 1016(67.64) \\
\hline Overweight & 18(9.00) & 182(91.00) & $200(13.32)$ \\
\hline Obese & $8(9.90)$ & 73(90.10) & $81(5.4)$ \\
\hline \multicolumn{4}{|l|}{ Wealth index } \\
\hline Poor & $41(15.83)$ & 218(84.17) & 259(17.24) \\
\hline Middle & $36(17.22)$ & 173(82.78) & 209(13.91) \\
\hline Rich & $121(11.70)$ & 913(88.30) & $1034(68.84)$ \\
\hline \multicolumn{4}{|l|}{ Maternal anemia } \\
\hline Not anemic & $147(14.78)$ & 994(87.12) & $1141(75.96)$ \\
\hline Mild & $7(8.54)$ & $75(91.50)$ & $82(5.46)$ \\
\hline Moderate & $9(14.06)$ & $55(85.94)$ & $64(4.26)$ \\
\hline Sever & $35(16.28)$ & 180(83.72) & $215(14.31)$ \\
\hline \multicolumn{4}{|l|}{ Sex of infant } \\
\hline Male & $84(10.93)$ & 684(89.06) & 768(51.13) \\
\hline Female & $114(15.51)$ & $621(84.49)$ & $735(48.97)$ \\
\hline
\end{tabular}

Table 5: Multi-level logistic regression analysis of individual and community-level factors associated with low birth weight in Ethiopia, EDHS 2016. 


\begin{tabular}{|c|c|c|c|c|}
\hline Characteristics & Model I & Model II & Model III & Model IV \\
\hline Fixed effects & & AOR $(95 \% \mathrm{Cl})$ & AOR $(95 \% \mathrm{Cl})$ & AOR $(95 \% \mathrm{Cl})$ \\
\hline Maternal age & - & & & \\
\hline $15-19$ & - & $1.77(0.82,4.74)$ & - & $1.90(0.79,4.59)$ \\
\hline $20-24$ & - & $1.05(0.52,2.12)$ & - & $1.01(0.50,2.06)$ \\
\hline $25-29$ & - & $1.13(0.57,2.21)$ & - & $1.09(0.56,2.15)$ \\
\hline $30-34$ & - & $0.91(0.45,1.81)$ & - & $0.90(0.45,1.79)$ \\
\hline $35-39$ & - & $0.75(0.35,1.59)$ & - & $0.74(0.34,1.56)$ \\
\hline $40-49$ & & 1 & - & 1 \\
\hline \multicolumn{5}{|c|}{ Women educational level } \\
\hline No education & - & $1.91(1.23,2.93)$ & - & $1.82(1.12,2.96)$ * \\
\hline Primary & - & $1.32(0.91,1.92)$ & - & $1.33(0.91,1.95)$ \\
\hline Secondary and above & - & 1 & - & 1 \\
\hline \multicolumn{5}{|l|}{ Gestational age } \\
\hline$<37$ weeks & - & $5.82(3.18,10.60)$ & - & $5.91(3.21,10.10)$ ** \\
\hline$\geq 37$ weeks & - & 1 & - & 1 \\
\hline \multicolumn{5}{|l|}{ Iron } \\
\hline Yes & - & 1 & - & 1 \\
\hline No & - & $1.15(0.84,1.57)$ & - & $1.14(0.83,1.57)$ \\
\hline \multicolumn{5}{|l|}{ Number of ANC visit } \\
\hline$<4$ visits & - & $1.08(0.79,1.51)$ & - & $1.11(0.80,1.52)$ \\
\hline$\geq 4$ visits & - & 1 & - & \\
\hline \multicolumn{5}{|l|}{ Media exposure } \\
\hline Yes & - & 1 & - & 1 \\
\hline No & - & $0.89(0.61,1.30)$ & - & $0.84(0.55,1.29)$ \\
\hline Maternal BMI & - & & & \\
\hline Underweight & - & $0.94(0.62,1.42)$ & - & $0.96(0.63,1.45)$ \\
\hline Normal & & 1 & & 1 \\
\hline Overweight & & $0.92(0.59,1.42)$ & & $0.92(0.59,1.42)$ \\
\hline Obese & - & $0.92(0.48,1.78)$ & - & $0.92(0.47,1.77)$ \\
\hline \multicolumn{5}{|l|}{ Wealth index } \\
\hline Poor & - & $1.16(0.73,1.83)$ & - & $1.26(0.674,1.438)$ \\
\hline Middle & - & $1.34(0.80,2.25)$ & - & $1.28(0.724,2.284)$ \\
\hline Rich & - & 1 & - & 1 \\
\hline \multicolumn{5}{|l|}{ Maternal anemia } \\
\hline Not anemic & - & 1 & - & 1 \\
\hline Mild & - & $0.64(.33,1.22)$ & - & $0.63(0.33,1.22)$ \\
\hline Moderate & - & $1.07(0.56,2.05)$ & - & $1.09(0.57,2.08)$ \\
\hline Severe & - & $1.48(1.04,2.11)$ & - & $1.47(1.04,2.01)$ \\
\hline \multicolumn{5}{|l|}{ Sex of infant } \\
\hline Male & - & 1 & - & 1 \\
\hline Female & - & $1.37(1.04,1.84)$ & - & $1.38(1.04,1.84)^{\star}$ \\
\hline \multicolumn{5}{|l|}{ Community poverty level } \\
\hline Low & - & - & 1 & 1 \\
\hline
\end{tabular}

Page 11/16 


\begin{tabular}{|lcccc|}
\hline High & - & - & $0.93(0.59,1.47)$ & $0.79(0.47,1.35)$ \\
\hline Community media exposure & & & & \\
\hline Low & - & - & $1.34(0.81,2.02)$ & $1.20(0.76,1.89)$ \\
\hline High & - & - & 1 & 1 \\
\hline Community women education & - & - & & \\
\hline Low & - & - & $0.79(0.52,1.20)$ & $0.83(0.52,1.30)$ \\
\hline High & - & - & 1 & 1 \\
\hline Place of residence & - & - & 1 & 1 \\
\hline Urban & - & - & $1.09(0.71,1.68)$ & $1.01(0.62,1.60)$ \\
\hline Rural & - & & \\
\hline
\end{tabular}

AOR;adjusted odds ratio, Cl;confidence interval,1;referencecategory, ${ }^{*}: \mathrm{p}$-value $<0.05,{ }^{\star \star *} \mathrm{p}$ value $<=0.01$

\section{Figures}

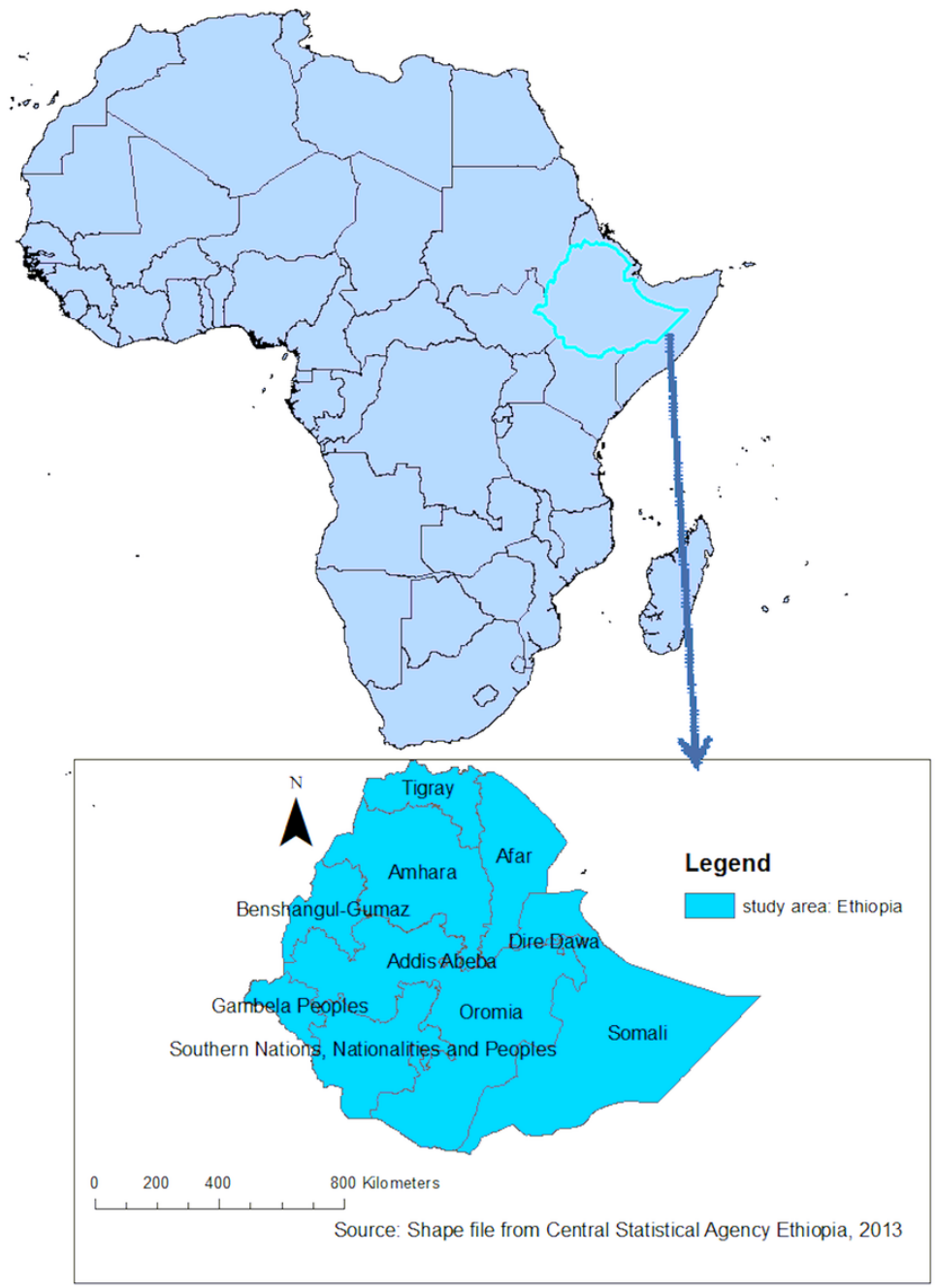

Figure 1

Figure 1 


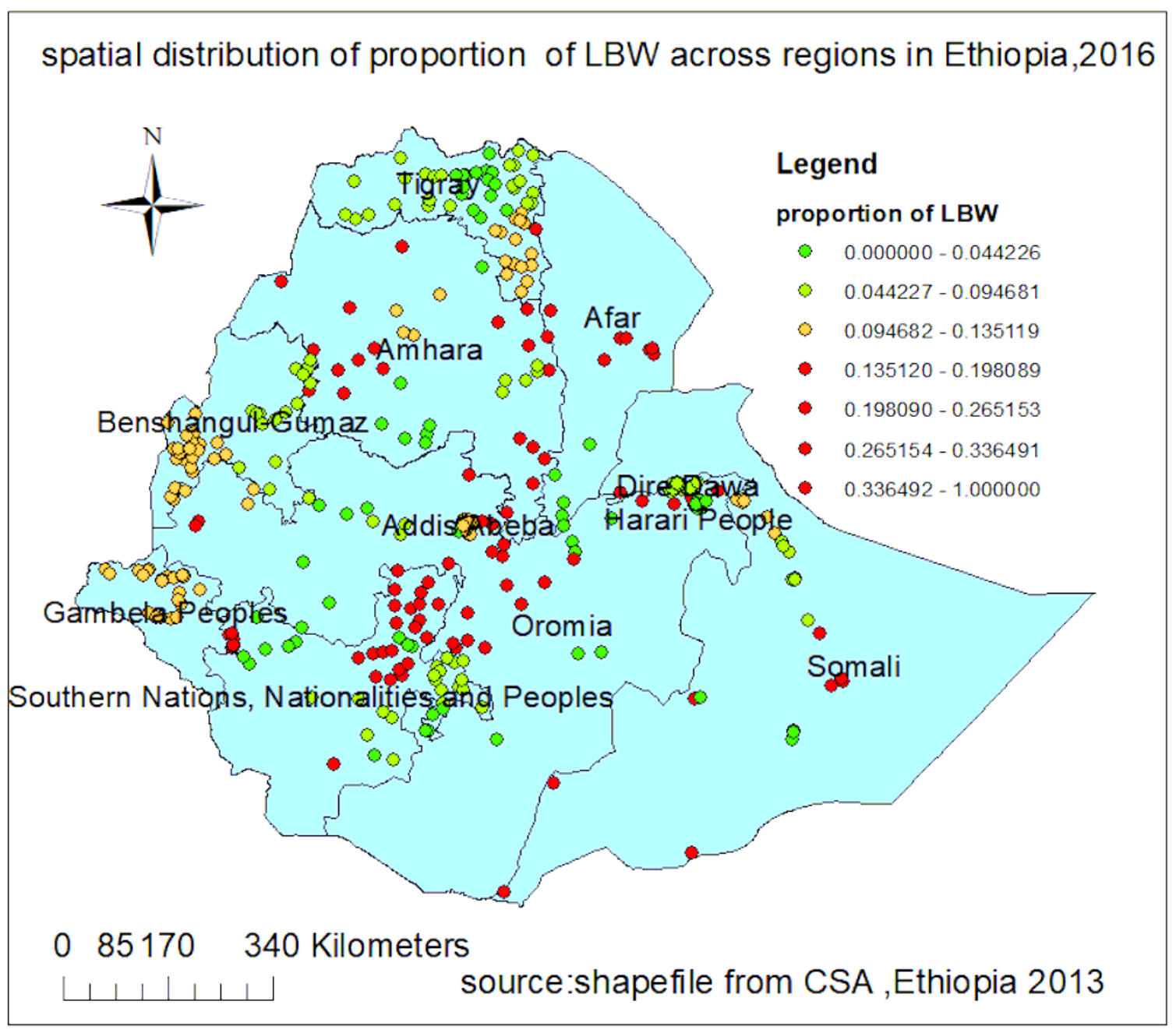

Figure 2

Spatial distribution of low birth weight in Ethiopia. 


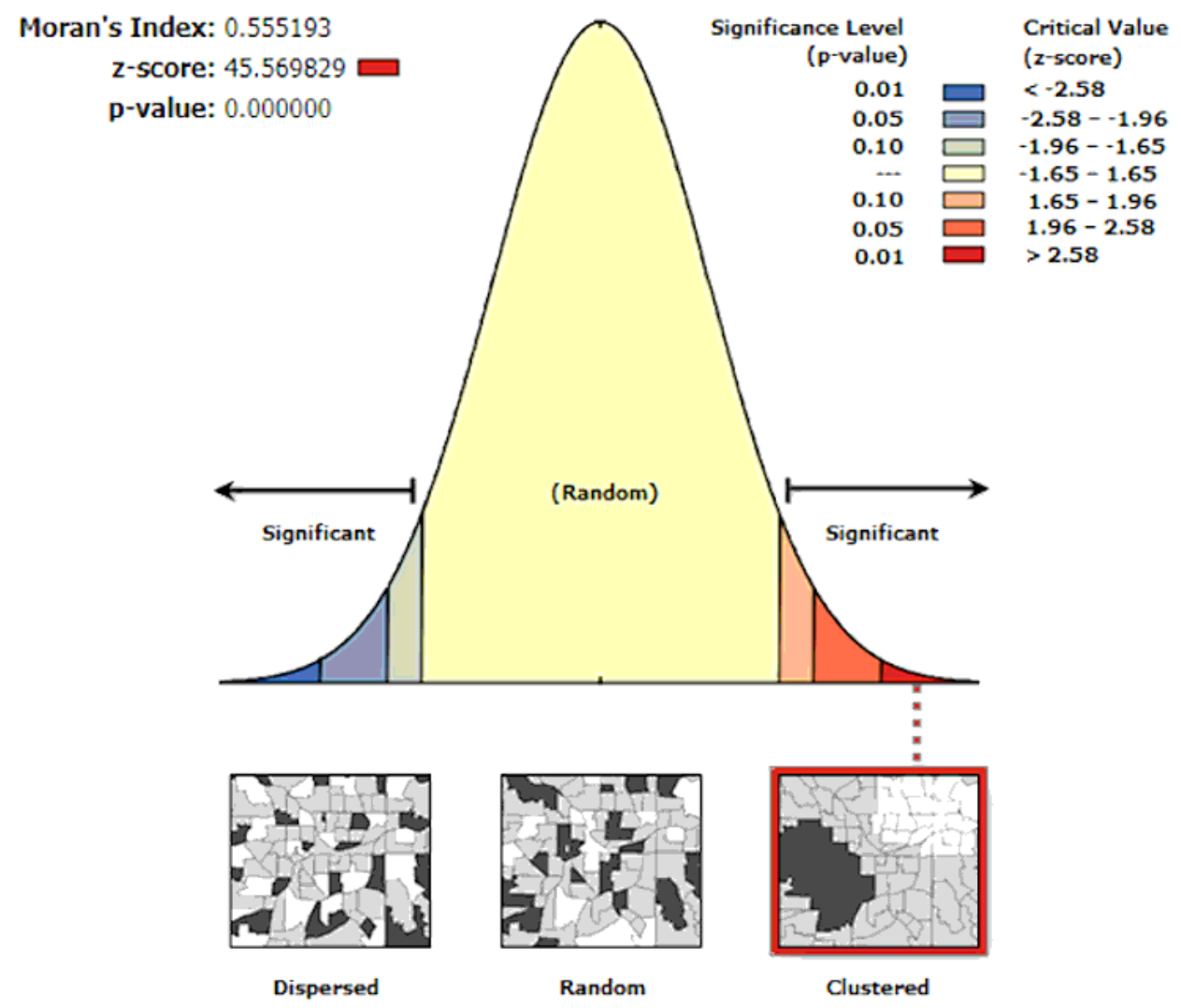

Figure 3

Spatial autocorrelation of low birth weight in Ethiopia, EDHS 2016 
Spatial scan statistics of low birth weight across regions in Ethiopia
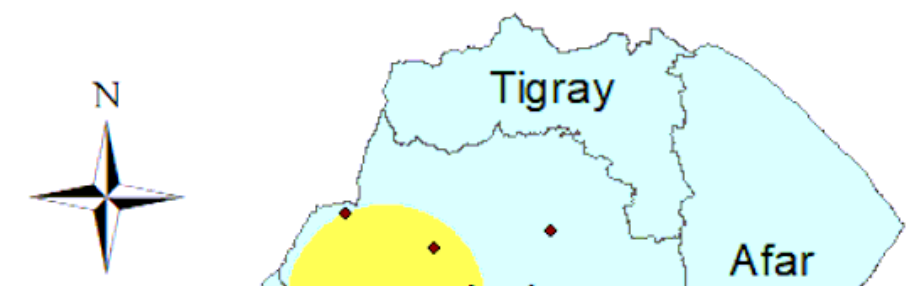


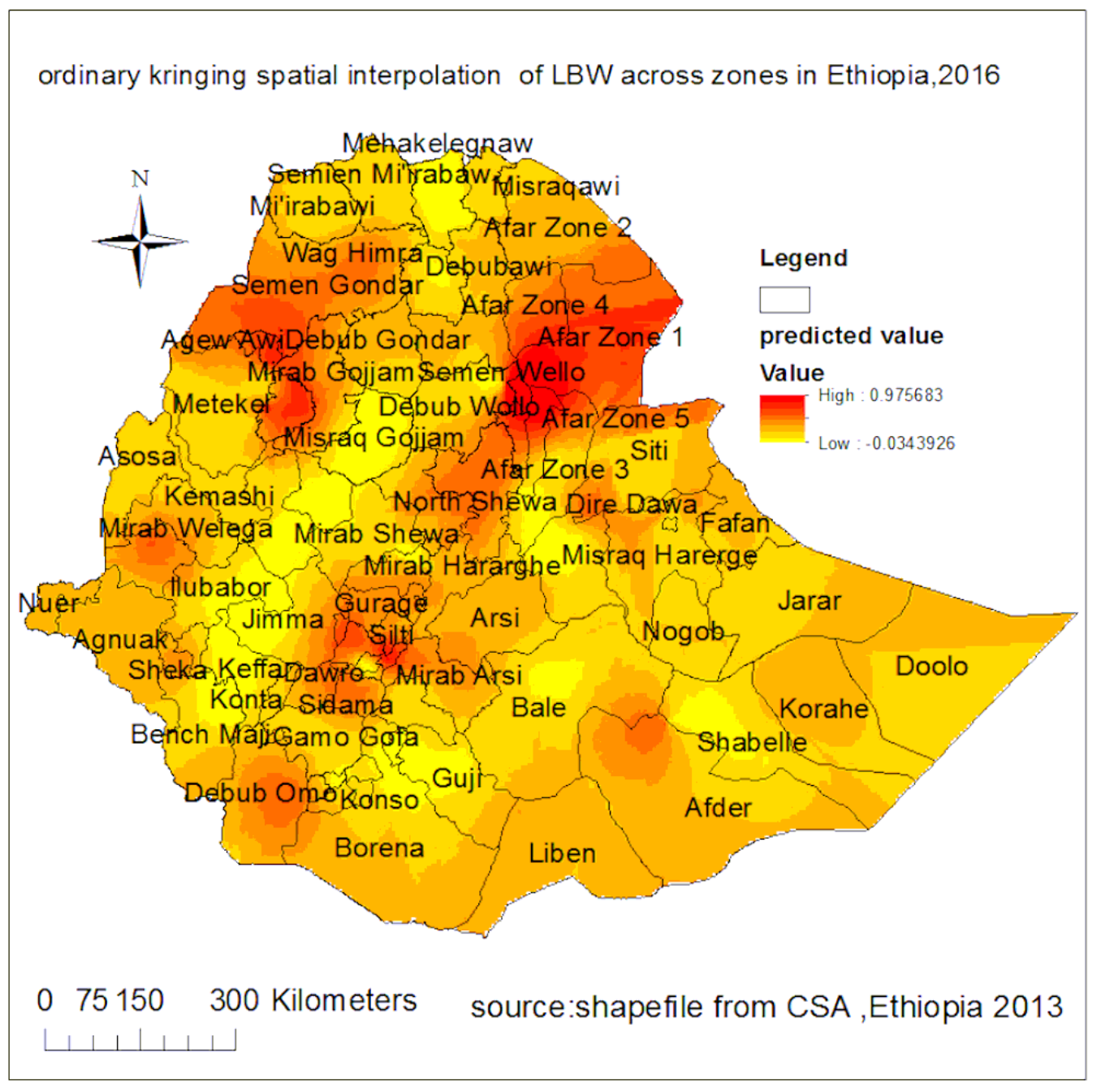

Figure 5

the ordinary kriging spatial interpolation of LBW across regions in Ethiopia, EDHS 2016. 